\title{
Alternative Fuel from Agricultural Waste Omprakash Sahu
}

Department of Chemical Engineering, KIOT, Wollo University, Ethiopia Correspondence Email:ops0121@gmail.com.

\section{Abstract:}

Waste can be minimized by reuse or recover by the process due disposal of the waste is big issue for environment. So many organization are working for to utilized the waste for energy recovery. Field crops offer potential source of fuel, offering promise as large-scale energy and based on its genetic diversity, climatic adaptation, and biomass and sugar production. Lignocellulosic biomass is the most abundant organic raw material in the world. Production of ethanol from renewable lignocellulosic resources may improve energy availability, decrease air pollution and diminish atmospheric $\mathrm{CO} 2$ accumulation. Presently this work was to evaluate the feasibility of ethanol production and optimization from Rice husk by using commercial bakery yeast, i.e., S. cereviciae. The experiment was conducted, at fermentation temperature $30^{\circ} \mathrm{C}$ and $\mathrm{pH} 5$, and treated using different acid concentrations and residence times. Rice husk was hydrolyzed by refluxing, a solid to liquid ratio of $1: 10$, using dilute sulfuric acid (1 to $5 \%$ ) and distilled water at hydrolysis time of 1 to 11 hours keeping boiling temperature. $90 \%$ maximum total sugar concentration was obtained at $5 \mathrm{~h}$ acid free hydrolysis. Based on these hydrolysis results, fermentation process was performed.

Keywords; Agriculture waste; Ethanol; Fermentation; Hydrolysis; Sugar

\section{Council for Innovative Research}

Peer Review Research Publishing System

Journal: Journal of Advances in Biotechnology

Vol 1, No. 2

editor@cirworld.com

www.cirworld.com, member.cirworld.com 


\section{Introduction}

Ethiopia is a rural based country and nearly about $65 \%$ populace is living in villages. Farming is the basic source for earning which requires energy as an intensive measure for production. To avoid the circumstances of the power, another way is use of the renewable energy sources [1]. The villages in the country are naturally endowed with variety of natural energy sources, by which means it is possible to develop self energy generating villages to satisfy the energy demand.

The villages in the country have strong and abundant natural energy sources. The biomass in villages is available in variety of forms [2]. The crop residue and livestock waste and the forest excess wood are main available sources of biomass in the villages. Biomass energy sources may be able to offer socio-economical and technical benefits compared to other renewable energy sources. Biomass source is the emerging energy among renewable energy sources having potential to fulfill the energy demand of the rural areas to enhance the rural economy in developing countries [3]. A potential source for low cost ethanol production is to utilize lignocellulosic materials such as crop residues, grasses, sawdust, wood chips, solid animal waste and industrial wastes [4]. The flow diagrame of ethanol production is shown in

Fig. 1.

Sugar Platform:

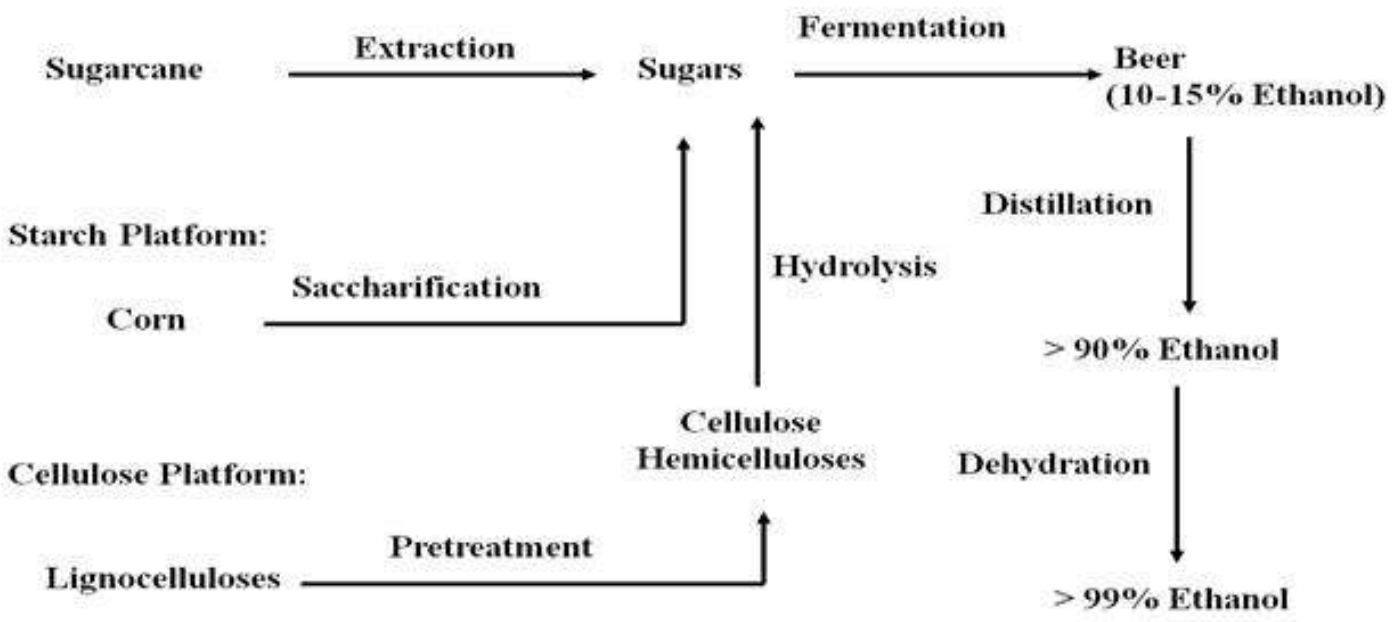

Fig. 1: Flow diagram for ethanol production

It has great potentials for the production of affordable fuel ethanol because it is less expensive than starch (e.g. corn) and sucrose (e.g. sugarcane) producing crops and available in large quantities. Lignocellulosic biomass typically contains $50 \%-80 \%$ (dry basis) carbohydrates that are polymers of $5 \mathrm{C}$ and $6 \mathrm{C}$ sugar units. Most carbohydrates can be processed either chemically or biologically to yield biofuels such as ethanol. Ethanol is a renewable energy source produced through fermentation of sugars. A dramatic increase in ethanol production using biomass based technology [6]. The prerequisite in the utilization of lignocellulose for ethanol production is to efficiently yield a fermentable hydrolyzate rich in glucose from the cellulose content present in the feedstock. Employment of enzymes for the hydrolysis of lignocellulose is considered the prospectively most viable strategy to offer advantages over other chemical conversion routes of higher yields, minimal byproduct formation, low energy requirements, mild operating conditions, and environmentally friendly processing [7].

One way of reducing environmental effects and the dependence on fossil fuels is to use renewable bioethanol. Apart from a very low net emission of $\mathrm{CO} 2$ to the atmosphere, the combustion of bioethanol in general results in the emission of low levels of non-combusted hydrocarbons, carbon monoxide (CO), nitrogen oxides and exhaust volatile organic compounds [8]. However, of environmental concern regarding the increased use of ethanol fuels is the increased exhaust emission of reactive aldehydes, such as acetaldehyde and formaldehyde. Thus, a key factor with respect to the possible effects of ethanol on urban air quality will be the durability and effectiveness of catalyst systems for aldehyde control.

Today, all cars with a catalyst can be run on a mixture of $90 \%$ gasoline and $10 \%$ ethanol without adjusting the engine. New cars can even use mixtures containing up to $20 \%$ ethanol. There are also new engines available that can run on pure ethanol, and so-called flexible fuel vehicles that are able to use mixtures of $0-85 \%$ ethanol in gasoline (E85). Ethanol can also replace diesel fuel in compression-ignition engines. However, to be able to mix diesel with ethanol an emulsifier is needed. Fuel ethanol is used in a variety of ways; however, the major use of ethanol today is as an oxygenated fuel additive [9]. Mixing ethanol and gasoline has several advantages. The higher octane number of ethanol (96-113) increases the octane number of the mixture, reducing the need for toxic, octane-enhancing additives. Ethanol also provides oxygen for the fuel, which will lead to the reduced emission of $\mathrm{CO}$ and non-combusted hydrocarbons. So, even though ethanol has only about two-thirds of the volumetric energy content of gasoline, it will still be possible to drive 75$80 \%$ of the distance on a given volume of ethanol [10].

The exact predication of the socio-economic benefit has not yet been completed in Ethiopia and could help to guide level of additional subsidies that may be appropriate for bioenergy compared to the other renewable energy sources. In this regard's an attempted has been made to utilize the biomass or agricultures waste for the production of bioethanol. The 
aim of this work was to study the optimum hydrolysis of Rice husk with diluted sulfuric acid and distilled water, and determining the influence of acid concentration and retention times. Also to evaluate the feasibility of ethanol production by fermentation of Rice husk by using commercial bakery yeast such as Saccharomyces cereviciae.

\section{Material and methods}

\subsection{Material:}

The Rice husk was arranged from the local area. The husk was oven-dried at $60{ }^{\circ} \mathrm{C}$ for $48 \mathrm{~h}$ (to moisture content of $15 \%$ ), grinded by coffee grinder and sieved [11]. The samples were stored in hermetically closed plastic containers at room temperature, until required for treatments. Erlenmeyer flasks, round bottom flask, yeast (S. cereviciae), sulfuric acid, sodium hydroxide, Fehling solution, methyl blue, pH-meter, thermometer, micropipette, measuring cylinder, Isopropanol (99\%), ethanol (96\%), gas chromatography, and icebox were used during the study.

\subsection{Methods:}

\subsubsection{Hydrolysis:}

Rice husk was hydrolyzed with dilute sulfuric acid $\left(\mathrm{H}_{2} \mathrm{SO}_{4}\right)$ at different concentrations (1 to $\left.5 \% \mathrm{H}_{2} \mathrm{SO}_{4}\right)$. In order to break down the cellulose and hemicelluloses into simple sugar the ground Rice husk sample was maintained at solid to liquid ratio of $1: 10$, in $250 \mathrm{~mL}$ round bottom flask, and refluxed, retaining samples of $1,2,4,6$ and $10 \mathrm{~h}$ for subsequent fermentation experiments. Similarly, the hydrolysis experiment was repeated with distilled water without using dilute sulfuric acid. After hydrolysis the liquid fraction of the hydrolysate samples were cooled, filtered, collected, and their sugar composition determined by Fehling method.

The distilled water and dilute sulfuric acid hydrolysates were adjusted to $\mathrm{pH} 5$ by adding concentrated sulfuric acid and $2 \mathrm{~N}$ Sodium hydroxide, and the solutions were prepared for fermentation [12].

\subsubsection{Fermentation:}

The yeast $S$. cereviciae, purchased from local market which was used in experiments. After hydrolysis, the flasks containing the hydrolyzed samples were covered with cotton wool, wrapped in aluminum foil, autoclaved for 15 minutes at $121^{\circ} \mathrm{C}$ and allowed to cool at room temperature. Fermentation was carried out in $250 \mathrm{~mL}$ Erlenmeyer flask with $3 \mathrm{~g} / \mathrm{L}$ of yeast (S. cereviciae) at incubation temperature of $30^{\circ} \mathrm{C}$ [13] Ethanol concentration was analyzed by gas chromatography at different fermentation times $(06$ to $50 \mathrm{~h}$ ). Samples were withdrawn every $6 \mathrm{~h}$ and the fermentation was carried out for 50 h.

\subsection{Analytical}

\subsubsection{Determination of Sugar Content:}

The amount of sugar in the hydrolyzed samples was determined by Fehling method. $50 \mathrm{~mL}$ of hydrolyzed sample solution was dissolved in $10 \mathrm{~mL}$ of distilled water and $2 \mathrm{~mL}$ of concentrated $\mathrm{HCl}$ was added and boiled. The obtained sample was neutralized with $\mathrm{NaOH}$ and the solution was made up to a volume of $300 \mathrm{~mL}$ and taken into the burette. The $5 \mathrm{~mL}$ of Fehling $A$ and $5 \mathrm{ml}$ of Fehling $\mathrm{B}$ were taken and mixed with $90 \mathrm{~mL}$ of distilled water in $250 \mathrm{~mL}$ Erlenmeyer flask and Methylene blue indicator was added. The solution in the flask was titrated with burette solution in boiling conditions until disappearance of blue color and the volume at which brick red color observed were recorded. For each sample the sugar content was calculated by using the formula given below.

\section{Sugar Content $(\%)=(300 \mathrm{~m} / x f / V) \times 100$}

Where, $f$ is Fehling factor and $V$ is volume used in the titration

\subsubsection{Ethanol concentration by gas chromatographic:}

The ethanol concentration was determined by gas chromatography. Gas chromatograph (DANI

GC 1000) equipped with flame ionization detector (FID) was employed for the separation and quantification of ethanol. A fused silica capillary column $(30 \mathrm{~m} \quad 0.32 \mathrm{~mm})$ coated with $95 \%$ methylpolysiloxane (stationary phase) was fitted into the instrument to provide on column injection. The injector and detector temperature were maintained at 210 and $250{ }^{\circ} \mathrm{C}$, respectively. The oven starting temperature was $50^{\circ} \mathrm{C}$, one minute hold time with heating rate of $30^{\circ} \mathrm{C}$ per minute to 155 ${ }^{\circ} \mathrm{C}$. Nitrogen was used as carrier gas at a flow rate of 0.5 bar and for $\mathrm{H} 2$ at 0.65 bar was adjusted. The concentration of ethanol in the samples was determined using isopropanol as internal standard

\section{Result and discussion}

\subsection{Effect of acid concentration}

The effect of acid concentration on the production of ethanol was carried out $1 \mathrm{~h}$ hydrolysis time is shown in Fig. 2. It was found that with the increasing the percentage of acid the concentration of ethanol was decreases. The maximum concentration ethanol was $6.8 \mathrm{~g} / \mathrm{l}$ was obtained when acid percentage was zero hydrolysis time $1 \mathrm{~h}$ and fermentation time 
$24 \mathrm{~h}$ respectively. After that ethanol concentration 5.7, 5.1, 4.7, 3.6, $2.9 \mathrm{~g} / \mathrm{l}$ decreases with increase in acid 1, 2, 3, 4, 5\% (percentage). This condition is similar where maximum amount of ethanol from distilled water hydrolysate than acid hydrolysates of Prosopis juliflora. This decrease in bioethanol concentration may account for the further sugar degradation that occurred under the severe acidity [14]. Overall, these results indicate that extreme acidity had an unfavorable effect on sugar conversion of rice husk.

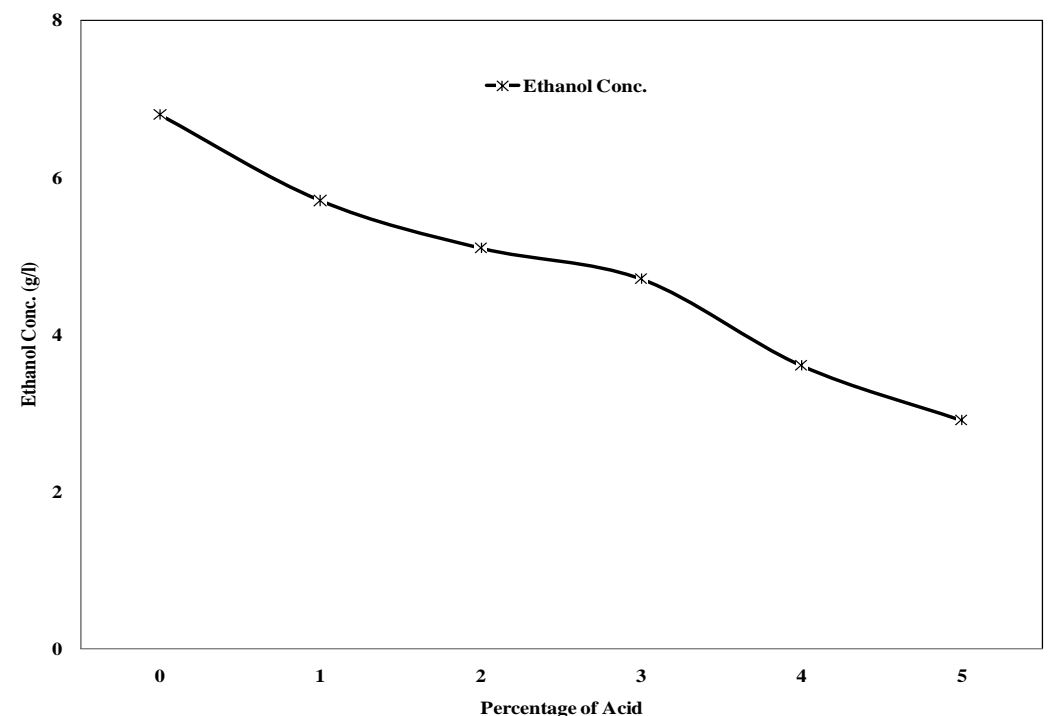

Fig. 2: Effect of acid concentration on ethanol production

\subsection{Effect of hydrolysis time}

The effect of hydrolysis on ethanol concentration was carried out zero percentage of acid at $24 \mathrm{~h}$ fermentation time, which is shown in Fig. 3. It maximum ethanol concentration $7.9 \mathrm{~g} / \mathrm{l}$ was found at $5 \mathrm{~h}$ hydrolysis time. When hydrolysis times are 1 and $3 \mathrm{~h}$ the ethanol concentration 5.7 and $6.4 \mathrm{~g} / \mathrm{l}$ was observed. Further increase in hydrolysis times $7,9,11 \mathrm{~h}$ the bioethanol concentration was $6.7,4.9,2.1 \mathrm{~g} / \mathrm{l}$ respectively. This attribute to that longer residence time makes the sugars degraded to form inhibitors (furfural and HMF) [14]. Therefore, distilled water hydrolysis and $5 \mathrm{~h}$ residence time were selected as the optimum conditions for hydrolysis of coffee pulp for bioethanol production.

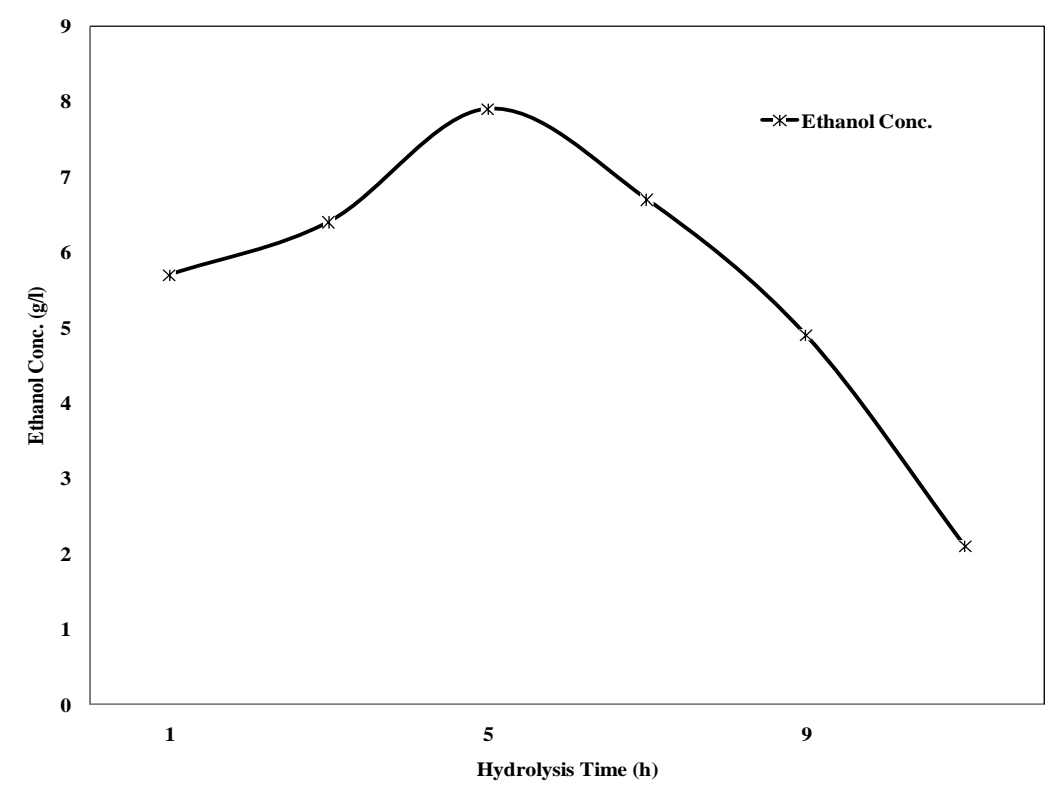

Fig. 3: Effect of hydrolysis time on ethanol production 


\subsection{Effect of fermentation time}

The effect of fermentation time on bioethanol concentration was carried out at $5 \mathrm{~h}$ hydrolysis time, which shown in Fig. 4.It was observed that $24 \mathrm{~h}$ is the optimum time for maximum yield of $7.9 \mathrm{~g} / \mathrm{l}$ bioethanol concentration. With the less fermentation time $6,12,18 \mathrm{~h}$ the ethanol concentration was $6.1,6.8,7.5 \mathrm{~g} / \mathrm{l}$ was observed. When fermentation time 30,36 , 42, 48, 54, 60h there no progress in the efficiency on bioethanol concentration i,e. 7.6, 7.1, 5.9, 4.7, 3.2, 1.8 g/l. This decrease in ethanol concentration with increase in fermentation time is might be due to the consumption of sugar by the microorganisms for ethanol production or the hydrolyzate does contain significant levels of metabolic inhibitors (e.g., furfural and HMF) that can interfere with fermentation [15].

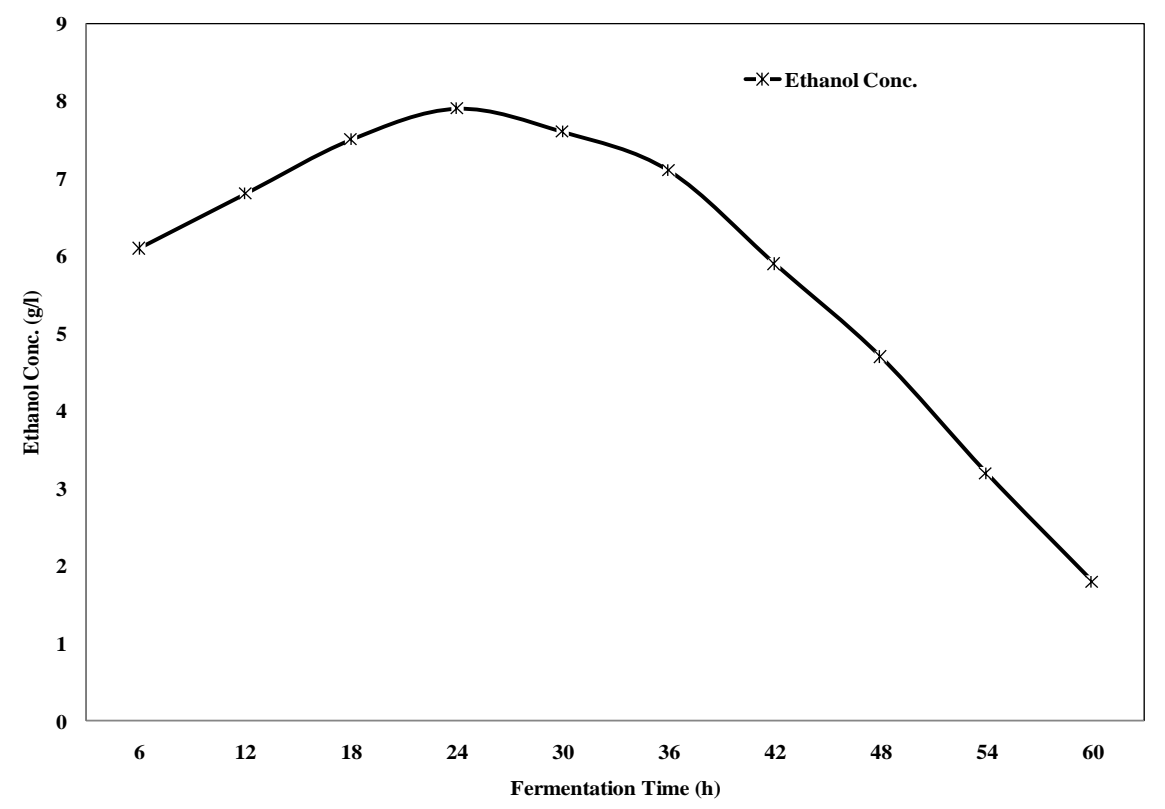

Fig. 4: Effect of fermentations on ethanol production

\section{Conclusion:}

Rice husk is promising lignocellulosic feedstock's for bioethanol production. One of the most important factors in the acid treatment of lignocellulose is the determination of optimal conditions required to provide the maximum yield of fermentable sugars and the least amount of inhibitors. In this study, the feasibility of ethanol production from Rice husk by means of dilute acid and distilled water hydrolysis techniques and ethanol fermentation time by $S$. cerevisiae was investigated. Dilute acid and distilled water hydrolysis was applied to produce simple sugars from Rice husk which followed by fermentation for production of bioethanol. The bioethanol production from Rice husk and optimization test have shown that distilled water is preferable than dilute acid hydrolysis. The optimization study showed that the highest bioethanol concentration of $7.9 \mathrm{~g} / \mathrm{l}$ was observed under the optimum conditions of with distilled water hydrolysis for $5 \mathrm{~h}$ by keeping boiling temperature with reflux, and fermentation time of $24 \mathrm{~h}$ held at $30^{\circ} \mathrm{C}$ with backer yeasts, which is appreciable.

\section{Reference}

[1] Sun, Y. and Cheng, J. (2002). Hydrolysis of lignocellulosic materials for ethanol production: a review. Biores. Technol. 83: 1-11.

[2] Oliveria, M., Vaughan, B. and Rykiel, J. (2005). Ethanol as fuel: energy, carbon dioxide balances, and ecological footprint. BioScience 55: 593-602.

[3] Govindaswamy, S. and Vane, L. (2007). Kinetics of growth and ethanol production on different carbon substrates using genetically engineered xylose-fermenting yeast. Biores. Technol. 98: 677-685.

[4] Paster, M. (2003). Industrial bioproduct: Today and tomorrow. U.S. Department of Energy, Office of Energy Efficiency and Renewable Energy, Office of the Biomass Program. Washington, D.C.

[5] AlemayehuTeshome, EsayasKebede and KassuKebede (2007). Coffee development and marketing improvement plan in Ethiopia. pp. 375-387. Proceeding of national workshop four decades of coffee research and development in Ethiopia, Addis Ababa.

[6] Urbaneja, G., Ferrere, J., Paeza, G., Arenas, L. and Colina, G. (1996). Acid hydrolysis and carbohydrates characterization of coffee pulp. Renew. Energy 9: 1041-1044. 
[7] Franca, A., Gouvea, B., Torres, C., Oliveira, L. and Oliveira, E. (2008). Feasibility of ethanol production from coffee husks. J. Biotechnol. 136: 269-275.

[8] Periyasamy, S., Venkatachalams, S., Ramasamy, S. and Srinivasan, V., (2009). Production of Bioethanol from Sugar Molasses Using S. cerevisiae. Modern Appl.Science 3: 32-36.

[9] Nutawan, Y., Phattayawadee, P., Pattranit, T. and Mohammad, N. (2010). Bioethanol Production from Rice Straw. Energy Research J. 1: 26-31.

[10] Weil, J., Dien, B., Bothast, R., Hendrickson, R., Mosier, N. and Ladisch, M. (2002). Removal of fermentation inhibitors formed during pretreatment of biomass by polymeric adsorbents. Ind. Eng. Chem. Res. 41: 6132-6138.

[11] Belkacemi, K., Turcotte, G. and Savoite, P. (2002). Aqueous/steamfractionated agricultural residues as substrates for ethanol production. Res. Ind. Eng. Chem. 41: 173-179.

[12] Davis, L., Jeon, Y. and Svenson, C. (2005). Evaluation of wheat stillage for ethanol production by recombinant Zymomonasmobilis. Biomass Bioenerg. 29: 49-59.

[13] Gunasekaran P. and Chandra K. (2007). Ethanol fermentation Technology: Zymomonasmobilis. Madurai Kamary University, Madurai, India. 1-22.

[14] Ohgrem K, Bura R, Lesnicki G et al (2007) A comparison between simultaneous saccharification and fermentation and separate hydrolysis and fermentation using steam pretreated corn stover. Process Biochem 42:834-839.

[15] Ballesteros, M., Oliva, J., Negro, M. and Manzanares, P. (2004). Ethanol from lignocellulosic materials by a simultaneous saccharification and fermentation process (SFS) with Kluyveromycesmarxianus CECT 10875. Process Biochem. 39:843-848. 